\title{
Development of Multipurpose Battery Operated Wheel Sprayer
}

\author{
Yomesh Sinha*, Jay Chauhan, Jayprakash Tandan, \\ Khirsagar Patel and Shakti Prakash Kaushik
}

Department of Farm Machinery and Power Engineering, Chhattisgarh Agricultural Engineering College, Dhanora, Bhilai, India

*Corresponding author

\begin{tabular}{|l|}
\hline Ke y w o r d s \\
Multipurpose \\
battery operated \\
wheel sprayer, \\
Pesticide, UPVC \\
Pipes \\
\hline Article Info \\
\hline $\begin{array}{l}\text { Accepted: } \\
\text { 15 October } 2019 \\
\text { Available Online: } \\
\text { 10 November } 2019\end{array}$ \\
\hline
\end{tabular}

\section{A B S T R A C T}

The Engine operated sprayer requires fuel which is very expensive due to this the operating cost of the engine operated sprayer is expensive and it emits the gases which is not ecofriendly. Now-a-days generally the knapsack sprayer is used by the Indian farmers. This type of sprayer consists of tank 10-20 liter capacity carried by two adjustable straps. In this knapsack sprayer developing adequate pressure is laborious, time consuming and it increase the drudgery of the farmers. In order to overcome these difficulties a battery operated sprayer has been proposed based on the general principle of spraying. This system is operated by direct current of battery. So we use pressure pump whose flow liquid capacity is 7.5LPM at pressure 120PSI (8bar). The developed multipurpose battery operated wheel sprayer comprises of $12 \mathrm{~V}$ and $12 \mathrm{AH}$ rechargeable battery; $12 \mathrm{~V}, 5 \mathrm{AH}$ pressure pump; charging unit and control switch.

\section{Introduction}

India itself to be an agricultural based country, approximately $75 \%$ of the population dependent on farming directly or indirectly. Farming is the backbone of Indian economy. Agriculture contributes about $18 \%$ to the total GDP and provides employment to over 50\% of the population but till now our farmers are doing farming in same traditional ways. There is need of development in this sector and most commonly on fertilizer pesticides spraying technique, because it requires more efforts and time to spray.

The agriculture sector is facing problems with capacity issues, shrinking revenues and labor shortages and increasing consumer demands. In addition, out of the 215.6million acres of irrigated land, around $44 \%$ is used for Herbs, and $13 \%$ is used for Shrubs, $14 \%$ for Climbers and others $5 \%$. The pest sprayers which are on 
the market can be used for any one of these sectors (Kiran et al., 2018). Our project focuses on all these sectors. Most farmers are seeking different ways to improve the equipment quality while reducing the direct overhead costs (labor) and capital. Pesticide sprayer must be portable, an increased tank capacity and it should be of less cost, labor and spraying time.

Spraying is an important operation to be performed by the farmer to protect the cultivated crops from insects, pest, funguses and diseases for which various pesticides, fungicides, insecticides and nutrients are sprayed on crops for crop protection. Spraying is the secondary tillage operation. A sprayer is a mechanical device used to spray the liquids like herbicides, pesticides, fungicides. Pesticides are widely used in agricultural production to prevent or control pests, diseases, weeds, and other plant pathogens in an effort to reduce or eliminate yield losses and maintain high product quality. Although pesticides are developed through very strict regulation processes to function with reasonable certainty and minimal impact on human health and the environment, serious concerns have been raised about health risks resulting from occupational exposure and from residues in food and drinking water. Occupational exposure to pesticides often occurs in the case of agricultural workers in open fields and greenhouses, workers in the pesticide industry.

Pests and disease control in crop plants is a crucial component of agricultural production system. A large volume of pesticides is used in crop protection.

However, its application on different crops is a highly inefficient process in our country. The total active ingredient of the pesticides applied to a crop, only a small amount reaches the target pest. Remaining major portion is lost by drift, off-target losses and leaf runoff during the purpose of spraying. The unused and lost portion of the pesticides not only results in economic loss but also pollute air, water, soil and food resources.

The above facts clearly emphasize the importance of the efficiency and precision of pesticides delivery systems. The statement "Crop protection agents are only as good as the technique used to apply them" given by Ripper (1955) is, in fact, more relevant today than it was in his times (Fig. 1 and 2).

\section{Materials and Methods}

\section{Working principle of machine}

A sprayer used for spraying insecticides, pesticides and herbicides. It works on principle the air flows at high velocity through the tube when the plunger is pushed in a region of low pressure is created just above the tube due to the flow of air at a high speed, and it breaks the chemical solution in to fine droplets of effective size, distribute the droplets uniformly over the plants.

The chemicals are applying with sufficient pressure for positive reaching the plants, and regulating the amount of liquid applied on plants to avoid excessive application

\section{Design consideration}

The main part of the system were frame, pressure pump, liquid container, move mechanism, through this system, it was possible to simulate the factor affecting spraying operation and evaluating nozzle including the wheel and nozzle discharge, nozzle height, spraying pressure with the least cost, time and energy.

Regarding performance calculation and the obtained data, designing of the intelligent 
system for determining draft of the sprayer was done using mathematic calculation.

\section{Selection of material}

Multipurpose Battery Operated Wheel Sprayer consists of the following materials.

\section{UPVC pipes (Unplasticized Polyvinyl} Chloride)

UPVC is the Unplasticized PVC in which no plasticized is included. Hence it is very rigid pipes, less bendable and used for hard work because of their rigidity. A UPVC pipe is nearly rigid as iron pipe however it is easy to cut power tool. Pipes are durable, fire resistant and they are recyclable. It was used instead of cast iron for heavy-duty plumbing work.

It is incredibly resistant to chemical erosion, and it can handle a wide range of temperature. The whole frame was made of UPVC pipe. The high pressure hose pipe was made by braided PVC material.

\section{Plastic}

Plastic is a material consisting of wide range of synthetic or semi-synthetic organic compounds. It can be moulded in to solid objects. The plastic are made of natural materials such as cellulose, coal, natural gas, salt and crude oil through a polymerisation or poly-condensation. The pesticide tank, wheels and weedicide nozzle cum cap were made of plastic material.

\section{Brass}

Brass is the generic term for a range of copper -zinc alloys with differing combinations the basic modern brass is $67 \%$ copper and $33 \%$ zinc of following properties including strength, ductility, wear-resistance, hardness, colour, electrical and thermal conductivity, hygiene and corrosion resistance. The control valves are made up of brass material.

\section{Stainless steel}

Stainless steel is an alloy of iron with a minimum of $10.5 \%$ Chromium. Chromium produces a thin layer of oxide on the surface of steel known as "passive layer". This prevents any future corrosion of the surface. Increasing the amount of chromium gives an increasing the resistance to corrosion.

Stainless steel are also contains very less amount of carbon, silicon aluminium, nickel. The carbon is the main component of stain less steel. The boom spray nozzles were made of stainless steel materials.

\section{Components of multipurpose battery operated wheel sprayer}

Multipurpose Battery Operated Wheel Sprayer consists of the following parts

Frame

Battery

Pressure Pump

Controller Unit

Charging Unit

Nozzles

Wheels

Tank

Pressure Spray Hose Pipe

Control Valves

Weedicide Cap 


\section{Frame}

The frame was made by UPVC pipe. One, $3 / 4^{\text {th }}$ and half inch diameter pipe were used to fabricate the frame of machine. Similarly the other parts were fabricated with uPVC material.

Fittings like T-joint and elbow-joint were used with the same. For joining the different parts a PVC solvent was used.

\section{Battery}

The Battery capacity was $12 \mathrm{~V}$ and $12 \mathrm{AH}$, battery was used to store chemical energy and convert chemical energy into electrical energy.

\section{Pressure pump}

Pressure Pump unit was operated by current supply from battery. The battery operated sprayer had utilized a mini diaphragm pump which is of compact size, light weight, high pressure and extended service life and featuring a pressure or protection switch to allow automatic pressure limit protection. The specification of pump are Volts-12V, Ampere5.0A, flow liquid capacity-7.5LPM and pressure 120PSI.

\section{Controller unit}

Controller Unit is basically a plastic box containing the battery and pressure pump. It has on/off switches one of green colour and other one of red. A regulator knob was provided for control the pressure from the nozzles.

\section{Charging unit}

A charging socket was provided in the controller unit to quickly charge the battery. A charger is used for charging battery. The charging time depends on the battery capacity and on the charging power. The input of charger is $50 \mathrm{~Hz} 220 \mathrm{~V}-\mathrm{AC}$ and output is $12 \mathrm{~V}$ 1.7A-DC.

\section{Nozzle}

The function of spray nozzle was conversion of pressurized spray liquid into droplets for application of insecticides, pesticides and herbicides on the target area.

\section{Nozzles used}

Flat fan type

\section{Cut Nozzle}

\section{Flat fan type nozzle}

Flat fan nozzle stands for uniform liquid distribution and jet pressures. Particularly powerful jets are generated with spray angles up to $60^{\circ}$. Nozzles with small flow rates were especially suited for humidifying and spraying in general. The flow geometry of the nozzle allows producing accurate compact jets.

\section{Classes of flat fan nozzles}

Low-pressure nozzles

High-pressure nozzles

Flat fan nozzles produce cat-eye shaped or parabolic distribution patterns with different capacities. Hence nozzle tips have long and short side differences. For convenience reasons, their "cat-eye shaped" spray pattern is converted into the area of a circle. The datum so obtained from the conversion is called "equivalent nozzle tip diameter".

\section{Cut nozzle}

These are ideal for high application rates and speeds, because they produce wide-angle, flat 
fan pattern. Operating flood-jet nozzles at 525 psi minimize drift but pressure change critically affects the width of the spray pattern. Generally, the spray generated by the flood-jet is not as uniform as the flat-fan type.

\section{Wheels}

Tubeless tires are pneumatic tires that do not require a separate inner tube. Unlike pneumatic tires which use a separate tube, tubeless tires have continuous ribs molded integrally into the bead of the tires so that they are forced by the pressure of the air inside the tire to seal with flanges of the metal rim or plastic rim of the wheel.

\section{Tank}

A 18 liters capacity of tank was installed on the centre of the frame. It was a acid container which we used as a tank for chemicals to be stored for spraying. It was a hard plastic and very rigid, better for every climatic condition.

A opening was subjected on the top side for pouring the chemicals/micro-nutrients. The valve setup was implanted on the handle of the tank for ergonomic requirement.

A nylon belt was provided vertically for supporting the tank from displacing. It was light-weight and easy to carry container.

\section{Pressure spray hose pipe}

It was a 3-layers high pressure pipes used for supplying the chemical to the nozzle. They are conventional and most popular equipment's used world-wide, which are used for all types of sprayer sprays insecticides, pesticides, fungicides, herbicides etc. The internal diameter of pipe is $8.5 \mathrm{~mm}$ and the total length is used 2.73 meters.

\section{Control valves}

Valves were mounted on the tank handle for easy operation while using the spray machine. A T-shape pipe frame was made to implant the valves setting. There are total 3-valves, one for boom spray nozzle, second for herbicide spray nozzle and third one for exemplary use.

\section{Weedicide cap}

Weedicide cap was used to cover the drift area of the nozzle because of its wide angle spray area. This was provided to protect the row crops from getting harm due to the spraying of herbicides. This was a practice of local farmers which was observed and made to work in actual practice. This was practice considered under the weed management programs. So to control the weeds, spot spraying technique was adopted by the farmers in wide row cropping by spraying non-selective herbicides, to overcome the population of the weeds in the crops. Kept the above points in mind, a weedicide nozzle and a cap were provided for multi-purpose use of the machine. The development of multipurpose battery operated wheel sprayer was easy to assemble and fabricate with locally available materials. Its operation was very easy and it required very less force of power to push the sprayer because of the wheels. Therefore, one person (male or female) can easily operate it. The fabrication cost of the multipurpose battery operated wheel sprayer was low. The cost of the multipurpose battery operated wheel sprayer was approximately Rs.6500.Good progress of the work has been made successfully. 
Fig.1 D model of machine

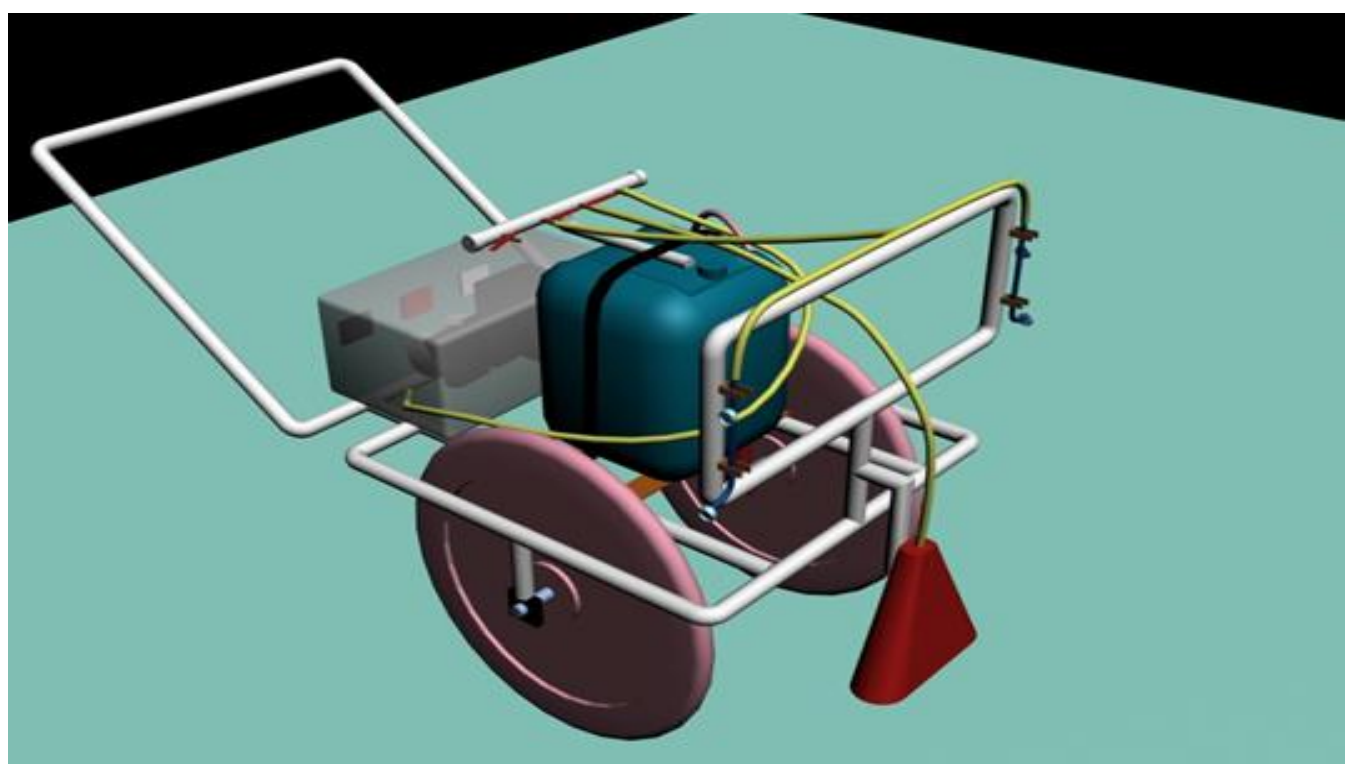

Fig.2 Developed machine

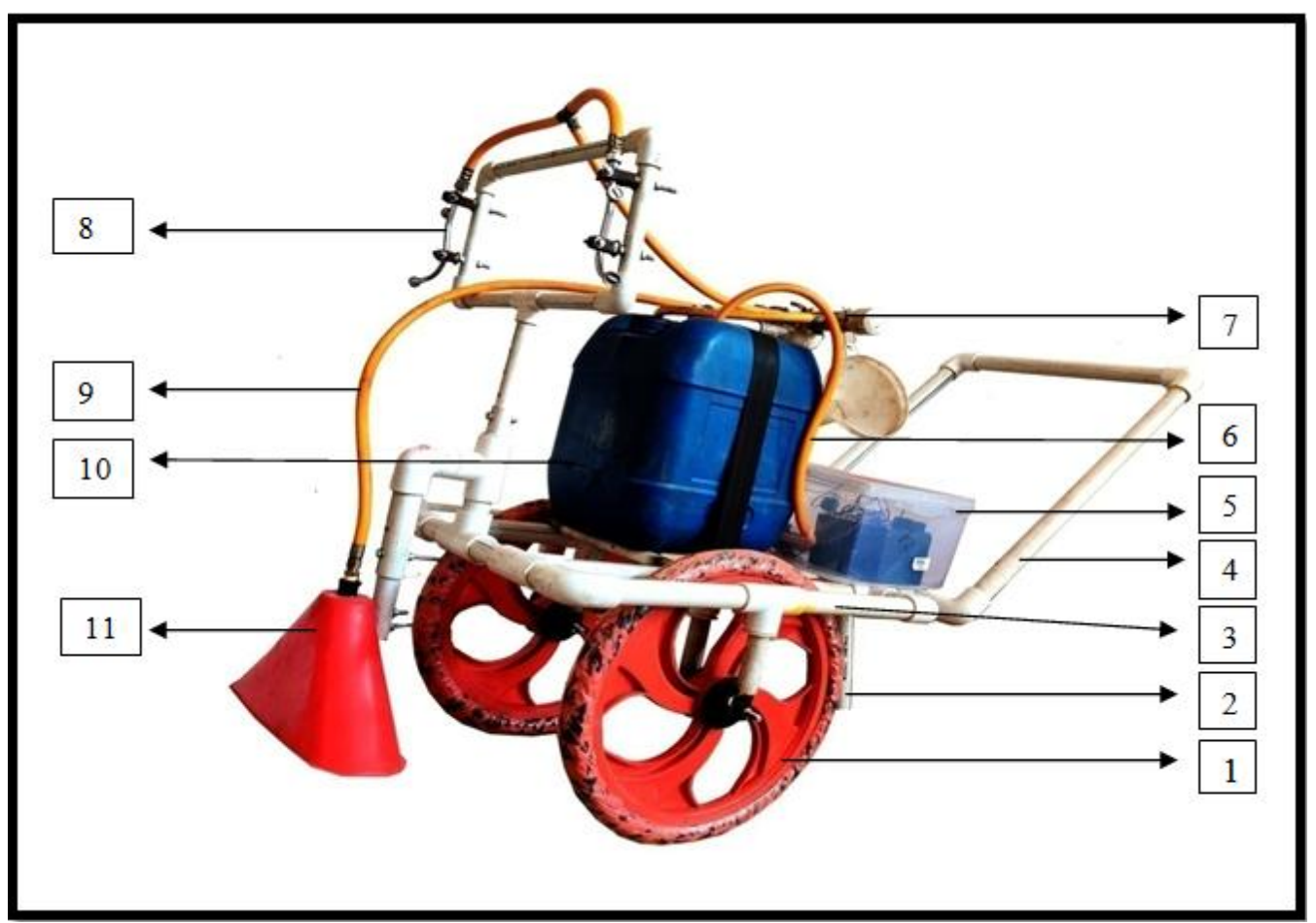

1.Wheel; 2.Stand; 3.Main Frame; 4.Handle; 5.Controller Unit; 6.Suction Hose Pipe; 7.Control Valves; 8.Flat Fan Nozzle; 9.Delivery Hose Pipe; 10.Tank; 11.Weedicide Cap with cut-nozzle inside.

\section{References}

Abilash Gurjar, Riyaz Mansuri, Sanjay Baghel and Kaustubh Kawale (1996). Solar powered sprayer. International Journal for Engineering Applications and Technology. 15: 2321-8134.

Abdula (1994). Optimum tilt angle and orientation for solar collectors in 
Assiut/Egypt.Renewable Energy. 4(3):291-298.

Arunkumar M, Kiran N, Rangaswamy N.S and Udedaravigouda (1996). Design and fabrication of portable solar operated chemical sprayer. Project reference no: $38 \mathrm{~S} 0442$.

Mada D.A.,Jamala G.Y. and Ibrahim S.(2013). Developed an ultra-low volume sprayer powered with dry cell battery. International Journal of Engineering and Science. 12:125-130.

Jayashree G.C. and Anantha D. Krishnan (2012). Tractor operated target actuated sprayer to reduce the offtarget application of chemical. African Journal of Agricultural Research.7:4952.

Avulu J.O. and Sohotshan P.Y. November (2012). Developed Electrically Operated Knapsack Sprayer. International Journal of Science and Technology. 2:11.

Khuram Ejaz (2004). A self-levelling boom sprayer to address the factors that chances the cost of production and other diverse effects. International Journal of Agriculture and Biology. 1560-8530/2004/06(4):636-638.

Kiran C H, Rajesh Sthavarmath, Abhishek, Raj Gowtham and Amar (2018). Fabrication of Multipurpose Pest Sprayer, International Journal of Research and Scientific Innovation (IJRSI). May 2018, 5(5):2321-2705.

Kshirsagar R.G, More S.N, Pawar V.V, Vasekar S.A (1996). Solar spray pump. ShriVithal Education \&
Research Institute, Pandharpur. 3(2): 487-490.

Dewangan K.N. (2006). Droplet spectrum of traditional lever operated knapsack (LOK) sprayer. Journal of Agricultural Engineering. 43(3) :840-855.

Laukik P. Raut and Smit B. Jaiswal (2013). Agricultural pesticide sprayer and weeder. International Journal of Applied Research and Studies. 2(2):11.

McAuliffe. D. and Gray V.P. (2002). Application Technology: Problems and Opportunities with knapsack Sprayers, Including the CF Valve or Constant Flow Valve. Global Agricultural Technology \& Engineering, LLC, Deerfield Beach, FL, USA. 5(2):125128.

McAuliffe. D. (1999). Flow control of lever operated knapsack sprayers with the CF Valve. International Pest Control. 41 (1):21-28.

ML. Suleiman et al., (2014).Spray parametric determination and testing of an animal drawn wheel-axle CDA Boom sprayer. Journal of Agriculture and Veterinary Science. 7(10):49-56.

Oladiran.,(1995). Mean global radiation captured by inclined collectors at various surface azimuth angles in Nigeria. Applied Energy.52(4):317330.

Omkarkargar, Gangaramgurav, Pramoddharade (1997). Solar seed sprayer + grass cutter + vacuum cleaner in a single unit. Project reference no: $37 \mathrm{~S} 0492$.

\section{How to cite this article:}

Yomesh Sinha, Jay Chauhan, Jayprakash Tandan, Khirsagar Patel and Shakti Prakash Kaushik. 2019. Development of Multipurpose Battery Operated Wheel Sprayer. Int.J.Curr.Microbiol.App.Sci. 8(11): 1766-1772. doi: https://doi.org/10.20546/ijcmas.2019.811.207 